\title{
A Lymphocyte Homing Receptor (L-Selectin) Mediates the In Vitro Attachment of Lymphocytes to Myelinated Tracts of the Central Nervous System
}

Kun Huang, Joyce S. Geoffroy, Mark S. Singer, and Steven D. Rosen

Department of Anatomy and Program in Immunology, University of California, San Francisco, California 94143-0452

\begin{abstract}
Lymphocytes enter lymph nodes by first adhering to high endothelial venules, an adhesive event mediated by a lectinlike lymphocyte receptor (L-selectin). Previously, it was shown with an in vitro assay that lymphocytes preferentially adhere to myelinrich regions in brain sections. Here, using a recombinant form of L-selectin as an immunohistochemical reagent, we demonstrate potential ligands for $\mathbf{L}$-selectin in myelinated regions of the central but not the peripheral nervous system. Using several antibodies and phorbol ester downmodulation of the receptor, we establish that L-selectin on human lymphocytes has a primary involvement in lymphocyte adherence to the myelinated regions. On mouse lymphocytes, the contribution of $\mathbf{L}$ selectin appears to be partial. These findings raise the possibility that leukocyte targeting to myelin-rich regions, via a L-selectin dependent mechanism, may be a factor in the pathogenesis of certain central nervous system demyelinating diseases. (J. Clin. Invest. 1991. 88:1778-1783.) Key words: L-selectin • lectin • myelin • multiple sclerosis • EAE
\end{abstract}

\section{Introduction}

Lymphocytes recirculate continuously throughout the body, passing through secondary lymphoid organs such as peripheral lymph nodes (PN) ${ }^{1}$ and Peyer's patches, which are interposed between the blood and lymphatics. The selective migration or homing of blood-borne lymphocytes to lymphoid organs depends on tissue-specific adhesive interactions with specialized endothelial cells (EC) of high endothelial venules (HEV) within the lymphoid organs (1-3). In the case of PN, the adhesion step is mediated by the interaction of a calcium-dependent, lectinlike receptor termed L-selectin (also known as LECAM-1, MEL-14 antigen, PN homing receptor, gp90 ${ }^{\mathrm{MEL}}$, LAM-1, Ly22, Leu-8, TQ1, and DREG) on the lymphocyte surface (4-11)

Address correspondence to Steven Rosen, Department of Anatomy, University of California, San Francisco, CA 94143-0452.

Received for publication 02 July 1991 and in revised form $09 \mathrm{Au}$ gust 1991.

1. Abbreviations used in this paper: CNS, central nervous system; EAE, experimental allergic encephalomyelitis; EC, endothelial cells; HEV, high endothelial venules; MLN, mesenteric lymph nodes; MS, multiple sclerosis; PN, peripheral lymph nodes.

J. Clin. Invest.

(c) The American Society for Clinical Investigation, Inc. 0021-9738/91/11/1778/06 \$2.00

Volume 88, November 1991, 1778-1783 and a carbohydrate-based ligand $(12,12 \mathrm{a})$ expressed by the EC of PN HEV cells. L-Selectin is a member of the "selectin" family of cell-cell adhesion proteins which also includes ELAM-1 (E-selectin) and CD62 (P-selectin) (13). A homing receptor distinct from L-selectin is used by lymphocytes to enter Peyer's patches (14-16) and another adhesion molecule appears to be involved in migration to chronic inflammatory lesions such as the synovium in rheumatoid arthritis (17).

The adhesive interactions between lymphocytes and HEV have been studied primarily with the Stamper-Woodruff assay (18), in which viable lymphocytes attach selectively to HEV structures within cryostat-cut sections of lymphoid organs. In the mouse, the ability of various lymphocyte populations to bind HEV within different lymphoid organs in vitro shows excellent correspondence with their migration to these tissues in vivo (19). The Stamper-Woodruff assay was recently applied to the study of B cell binding to germinal centers of tonsil, an interaction that may underlie the localization of activated $B$ cells to the follicles of lymphoid organs (20).

Several years ago, Kuttner and Woodruff employed the same assay to demonstrate that rat peripheral lymphocytes are able to adhere specifically to the white matter, but not to nonmyelinated regions, of both cerebellum and cerebrum (21). In contrast, thymocytes exhibit little binding activity to both myelinated regions and PN HEV. These parallels suggested that lymphocyte binding to $\mathrm{HEV}$ and to myelinated regions might involve the same lymphocyte surface receptors (21). It was speculated (21) that under pathological conditions (e.g., multiple sclerosis) in which leukocyte trafficking to the central nervous system (CNS) compartment occurs, the presence of myelinbinding receptors might promote the accumulation of these cells at myelinated regions and might therefore be a factor in the pathogenesis of demyelination. A possible indication of the pathophysiological relevance of the original observations was that lymphocytes from MS patients adhere significantly better than control lymphocytes to myelinated regions of brain sections (22).

The role of L-selectin in lymphocyte binding to PN HEV was initially inferred from antibody blockade studies performed with the Stamper-Woodruff adherence assay (4). Subsequent studies confirmed this function by showing that both the purified molecule (23) and LEC-IgG (a soluble fusion protein of murine L-selectin and human IgG) (24) can selectively interact with PN HEV and block lymphocyte attachment. Moreover, LEC-IgG was employed as the basis of a specific histochemical stain for the HEV-associated ligand molecules for L-selectin (24). In the present study, we have employed previously established techniques to investigate whether Lselectin participates in lymphocyte binding to myelinated regions of the brain. 


\section{Methods}

Reagents. LEC-IgG was a gift from Dr. Larry Lasky (Genentech Inc. South San Francisco, CA). MEL-14 was purified by ammonium sulfate precipitation of hybridoma culture supernatant. PolyMEL was generated from a rabbit immunized with purified mouse L-selectin (25). Anti-mouse lymphocyte Peyer's patch HEV adhesion molecule-1 (LPAM-1) was used as supernatant of R1/2 (American Type Culture Collection, Rockville, MD). Anti-mouse T200 (M1/9.3) was a gift from Dr. Jeff Curtis (VA Medical Center, San Francisco, CA). TQ1 was obtained from Coulter Laboratories, Hialeah, FL. LAM1.4 was a gift from Dr. Tom Tedder (Dana-Farber Cancer Institute, Boston, MA). Anti-human integrin $\alpha_{4}$ (HP2/1) was obtained from AMAC, Inc. (Westbrook, ME). Anti-human integrin $\beta_{2}$ was purchased from Telios Pharmaceuticals, Inc. (San Diego, CA). Anti-human integrin $\beta_{1}$ antibody, AIIB2 (26), was a gift from Dr. Caroline Damsky (University of California, San Francisco, CA). Cacodylic acid, EGTA, PMA, FITC, and paraformaldehyde were obtained from Sigma Chemical Co. (St. Louis, MO).

Cells and tissues. Mouse or rat mesenteric lymph node (MLN) lymphocytes were obtained from normal ICR mice (Bantin \& Kingman, Inc., Freemont, CA) or Sprague-Dawley rats (Simonsen Laboratories, Inc., Gilroy, CA). Human peripheral blood mononuclear leukocytes (PBL) were isolated from the peripheral blood of healthy volunteers using Mono-Poly Resolving Medium (Flow Laboratories, Inc., McLean, VA). JS9-78 (a cloned Jurkat line with high expression of L-selectin, a gift from Dr. Lloyd Stoolman, University of Michigan, Ann Arbor, MI) was cultured in RPMI 1640 supplemented with $10 \%$ FCS. Mouse cerebellum and spinal cord were obtained from ICR mice. A human cerebellum, which was formalin-fixed and stored in ethanol, was used for sectioning.

Histochemical staining using LEC-IgG. The method for LEC-IgG staining was described in detail elsewhere (24). Briefly, cryostat-cut sections $(10 \mu \mathrm{m})$ were fixed with $0.5 \%$ paraformaldehyde in $0.1 \mathrm{M}$ sodium cacodylate ( $\mathrm{pH} \mathrm{7.3)}$ for $20 \mathrm{~min}$ on ice, followed by immersion in $100 \%$ methanol with $0.3 \% \mathrm{H}_{2} \mathrm{O}_{2}$ for $20 \mathrm{~min}$ on ice. The sections were washed in Dulbecco's PBS and incubated for $80 \mathrm{~min}$ on ice with 30 $\mu \mathrm{g} / \mathrm{ml} \mathrm{LEC}-\mathrm{IgG}$ diluted in 5\% normal horse serum and 5\% normal rat serum. They were incubated with biotinylated-goat anti-human IgG (Zymed Laboratories, South San Francisco, CA) in PBS containing 5\% normal mouse serum followed by an $\mathrm{ABC}$ Elite reagent (Vector Laboratories, Inc., Burlingame, $\mathrm{CA}$ ), and then AEC peroxidase substrate (Biomeda, Foster City, CA). Finally, the sections were counterstained with aqueous hematoxylin (Biomeda) and photographed with a Nikon Optiphot microscope.

In vitro lymphocyte binding assay. Mouse MLN lymphocytes or Jurkat cells $\left(1-3 \times 10^{6}\right.$ cells in $100 \mu$ l of RPMI 1640 supplemented with 5\% FCS and $12.5 \mathrm{mM}$ Hepes) were incubated on paraformaldehydefixed tissue sections by a modification of the Stamper-Woodruff assay (27). Antibodies tested were added to the cell suspension before the incubation. The sections were then fixed in $2.5 \%$ glutaraldehyde and stained with toluidine blue. A unit area (UA, $0.032 \mathrm{~mm}^{2}$ ) was defined with the aid of an ocular reticle or as a defined myelin strip present on a series of contiguous tissue sections. In assays testing the effects of rat antibodies reactive to mouse L-selectin and LPAM-1, a ratio method was used in which rat lymphocytes (used as an internal control population) were labeled with $60 \mu \mathrm{g} / \mathrm{ml} \mathrm{FITC} \mathrm{in} \mathrm{PBS} \mathrm{for} 30 \mathrm{~min}$ at $37^{\circ} \mathrm{C}(28)$ and mixed with an equal number of mouse lymphocytes for the binding assay. Antibodies that were tested were present continuously during the binding assay. Inhibition of adherence was calculated from the change in the ratio of specifically bound mouse to rat cells.

\section{Results}

We extended the basic observation of Kuttner and Woodruff to other species by showing that mouse MLN lymphocytes (Fig. 1 a) and human Jurkat cells (Fig. 1 c) attach to the white matter tract of mouse cerebellum while exhibiting very limited binding to the grey matter region (granular layer) or to the dendritic region (molecular layer). Equally selective binding was also ob-
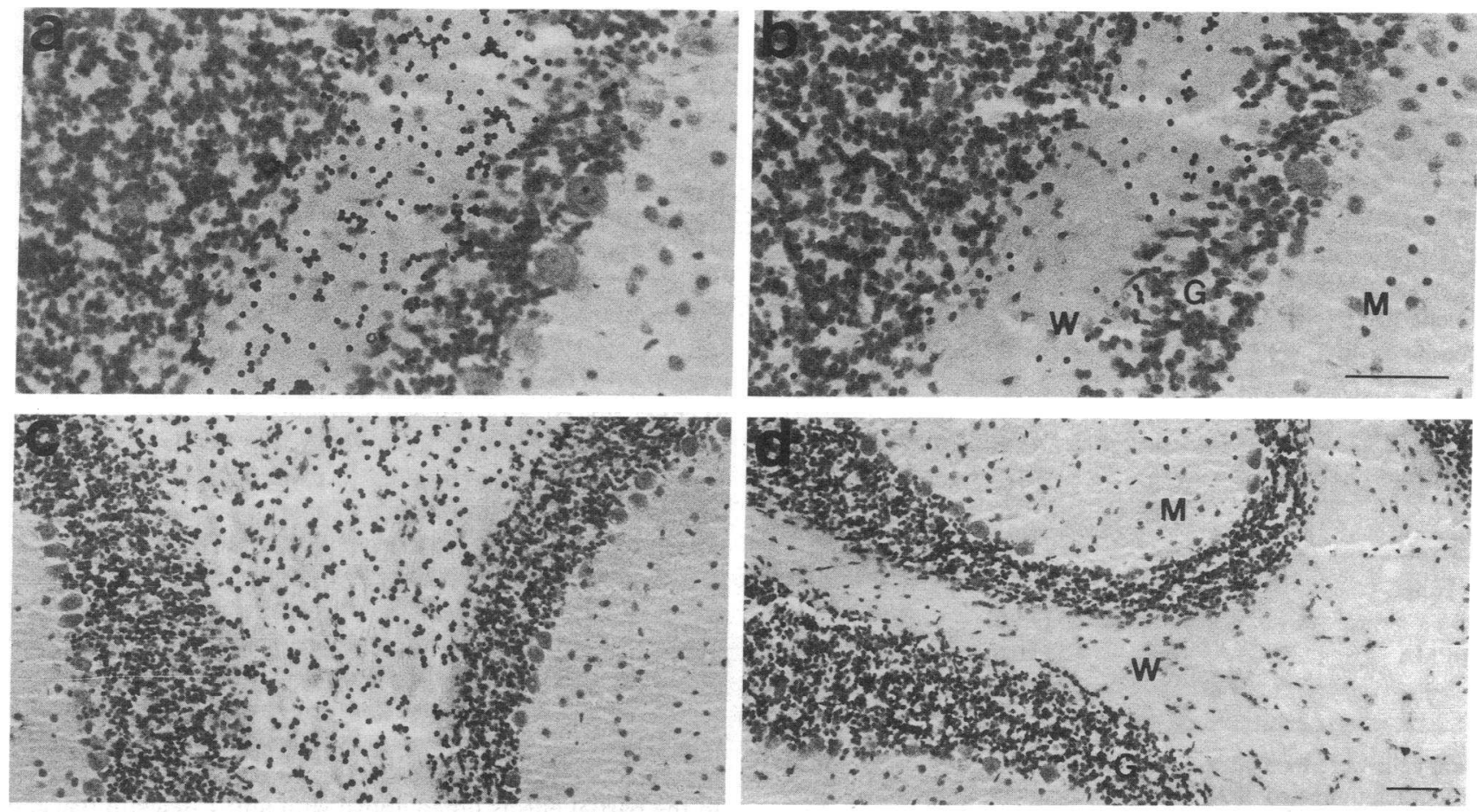

Figure 1. Binding of mouse lymphocytes and human Jurkat cells to mouse cerebellum. ( $a$ and $b$ ) Mouse MLN lymphocytes; ( $c$ and $d$ ) human Jurkat cells. ( $a$ and $c$ ) No EGTA added; ( $b$ and $d$ ) with $10 \mathrm{mM}$ EGTA. Exogenous lymphoid cells bound are shown as dark dots associated with white matter. $W$, white matter, $G$, granular layer, and $M$, molecular layer. Bars, $50 \mu \mathrm{m}$. 
Table I. Effects of Antibodies and EGTA on Lymphocyte Binding to Cerebellar White Matter

\begin{tabular}{|c|c|c|c|c|}
\hline Experiment & Cells for binding & Cerebellum source & - Reagent added & \% inhibition \\
\hline \multirow[t]{2}{*}{1} & Mouse MLNL & Mouse & MEL-14 & $27.4( \pm 4.8)$ \\
\hline & & & Anti- $\alpha_{4} \beta_{\mathrm{p}}$ & $2.47( \pm 6.5)$ \\
\hline \multirow[t]{3}{*}{2} & Mouse MLNL & Human & EGTA* $^{*}$ & $78.3( \pm 3.7)$ \\
\hline & & & MEL-14 & $32.9( \pm 14.7)$ \\
\hline & & & PolyMEL & $56.5( \pm 3.0)$ \\
\hline 3 & Human Jurkat & Mouse & TQ1 & $97.5( \pm 1.1)$ \\
\hline • & & & PolyMEL & $97.9( \pm 1.1)$ \\
\hline 4 & Human Jurkat & Mouse & LAM1.4 & $81.7( \pm 7.9)$ \\
\hline \multirow[t]{3}{*}{5} & Human Jurkat & Human & TQ1 & $98.9( \pm 0.3)$ \\
\hline & & & Anti- $\beta_{1}$ & $5.8( \pm 2.4)$ \\
\hline & & & Anti- $\beta_{2}$ & $13.9( \pm 4.5)$ \\
\hline \multirow[t]{4}{*}{6} & Human PBL & Mouse & EGTA & $95.5( \pm 1.5)$ \\
\hline & & & TQ1 & $98.1( \pm 0.6)$ \\
\hline & & & Anti- $\beta_{2}$ & $-15.2( \pm 7.2)$ \\
\hline & & & Anti- $\alpha_{4}$ & $-5.9( \pm 18.7)$ \\
\hline
\end{tabular}

Data are reported as mean percent inhibition of binding ( \pm SEM) relative to controls (no antibody or EGTA). Three to five replicate sections were used for each condition. Negative values denote percent increase of cell binding. In experiment 1 , the ratio method was used with an internal standard of fluorescein-labeled rat lymphocytes (see Methods). The antibodies were used at the following concentrations: MEL-14, $5 \mu \mathrm{g} / \mathrm{ml}$; PolyMEL serum, 1:10; LAM1.4, 1:100; TQ1, $10 \mu \mathrm{g} / \mathrm{ml}$. Anti-human $\beta_{1}, \beta_{2}$, and $\alpha_{4}$ were used at a saturating concentration for Jurkat cells as established by flow cytometry analysis. EGTA was used at $10 \mathrm{mM}$. The antibodies and EGTA were added to the cells immediately before incubation of the cells with the tissue sections and were present continuously during the binding assay. The control level of binding ranged from 100 to 300 cells per UA in the different experiments. MLNL denotes mesenteric lymph node lymphocytes. * In a separate experiment, EGTA produced $88 \pm 3 \%$ inhibition of mouse lymphocyte binding to mouse cerebellar white matter.

served to white matter tracts as compared to the grey matter regions of the spinal cord (not shown). Consistent with a possible role of a calcium-dependent adhesion molecule in the interaction, the addition of EGTA greatly reduced $(>80 \%)$ the binding of mouse lymphocytes to cerebellar white matter and completely prevented ( $>96 \%$ ) the adherence of Jurkat cells (Fig. 1, $b$ and $d$, Tables I and II). To determine if the myelinated regions contained potential ligands for L-selectin, brain and spinal cord sections were stained with LEC-IgG. As shown in Fig. 2 , the myelin-rich white matter tracts of both cerebellum and spinal cord exhibited specific staining. In contrast, regions having few or no myelinated fibers, such as the granular and molecular layers of the cerebellum and the grey matter of the spinal cord, were negative. In some instances, Purkinje cell bodies were slightly positive. In agreement with the known calcium dependency of L-selectin $(29,30)$, the addition of EGTA to

Table II. Effects of PMA on Jurkat Cell Binding to Human Cerebellar White Matter

\begin{tabular}{ccrr}
\hline Treatment of cells & EGTA & Cells bound/UA & \% inhibition \\
\hline \multirow{2}{*}{ None } & - & $117.0( \pm 4.1)$ & \\
& + & $2.5( \pm 1.0)$ & $97.9( \pm 0.8)$ \\
PMA & - & $4.5( \pm 0.6)$ & $96.2( \pm 0.6)$ \\
& + & $2.8( \pm 0.5)$ & $97.6( \pm 0.4)$
\end{tabular}

Jurkat cells were incubated with PMA at $100 \mathrm{ng} / \mathrm{ml}$ for $30 \mathrm{~min}$ at $37^{\circ} \mathrm{C}$, or left untreated under the same conditions, washed, and used for the binding assay. EGTA was used at $10 \mathrm{mM}$. Data represent the mean of cells bound per UA and percent inhibition $( \pm$ SEM) of four replicate sections. In the same experiment, PMA exposure of Jurkat cells completely inhibited their adhesion ( $90 \%$ ) to mouse PN HEV.
LEC-IgG greatly reduced staining of the myelinated regions as was previously observed for staining of PN HEV (24). Strikingly, the staining of myelinated fiber tracts appeared to be restricted to the CNS, because LEC-IgG reactivity was not detected on the nerve root adjacent to the white matter of spinal cord (Fig. $2 c$ ) or on the sciatic nerve (not shown).

To determine directly whether L-selectin on lymphocytes contributed to their binding to myelinated regions, we employed monoclonal and polyclonal antibodies against L-selectin. MEL-14 is a well characterized monoclonal antibody which recognizes mouse L-selectin and completely blocks mouse lymphocyte binding to PN HEV (4). As shown in Fig. 3, MEL-14 produced a partial inhibition (30\%) of mouse lymphocyte binding to cerebellum white matter (mouse or human), whereas the binding to PN HEV was almost completely eliminated. Anti-T200, a class-matched antibody reactive with the lymphocyte common antigen (CD45), had no effect on binding to either PN HEV or cerebellar myelin. Whereas MEL-14 inhibited $\sim 30 \%$ (ranging from 20 to $50 \%$ in different experiments) of lymphocyte binding to myelinated regions, EGTA caused $>80 \%$ inhibition (Fig. 1, Table I). PolyMEL is a rabbit polyclonal antiserum produced against murine $\mathrm{L}$-selectin that blocks adherence of lymphocytes from mouse, rat, and human origin to PN HEV (25). When tested on mouse lymphocyte binding to myelinated regions of cerebellum, PolyMEL also produced a partial inhibitory effect of $\approx 50 \%$ (Table I).

TQ1 and LAM 1.4 are recently described monoclonal antibodies that react with human L-selectin (31) and effectively interfere with lymphocyte attachment to PN HEV. In contrast to the partial effects noted above with anti-L-selectin reagents on mouse lymphocytes, TQ1 blocked (>90\%) the binding of both a Jurkat T cell line and human PBL to cerebellar myelin to the same extent as EGTA (Table I). Equivalent inhibitory 

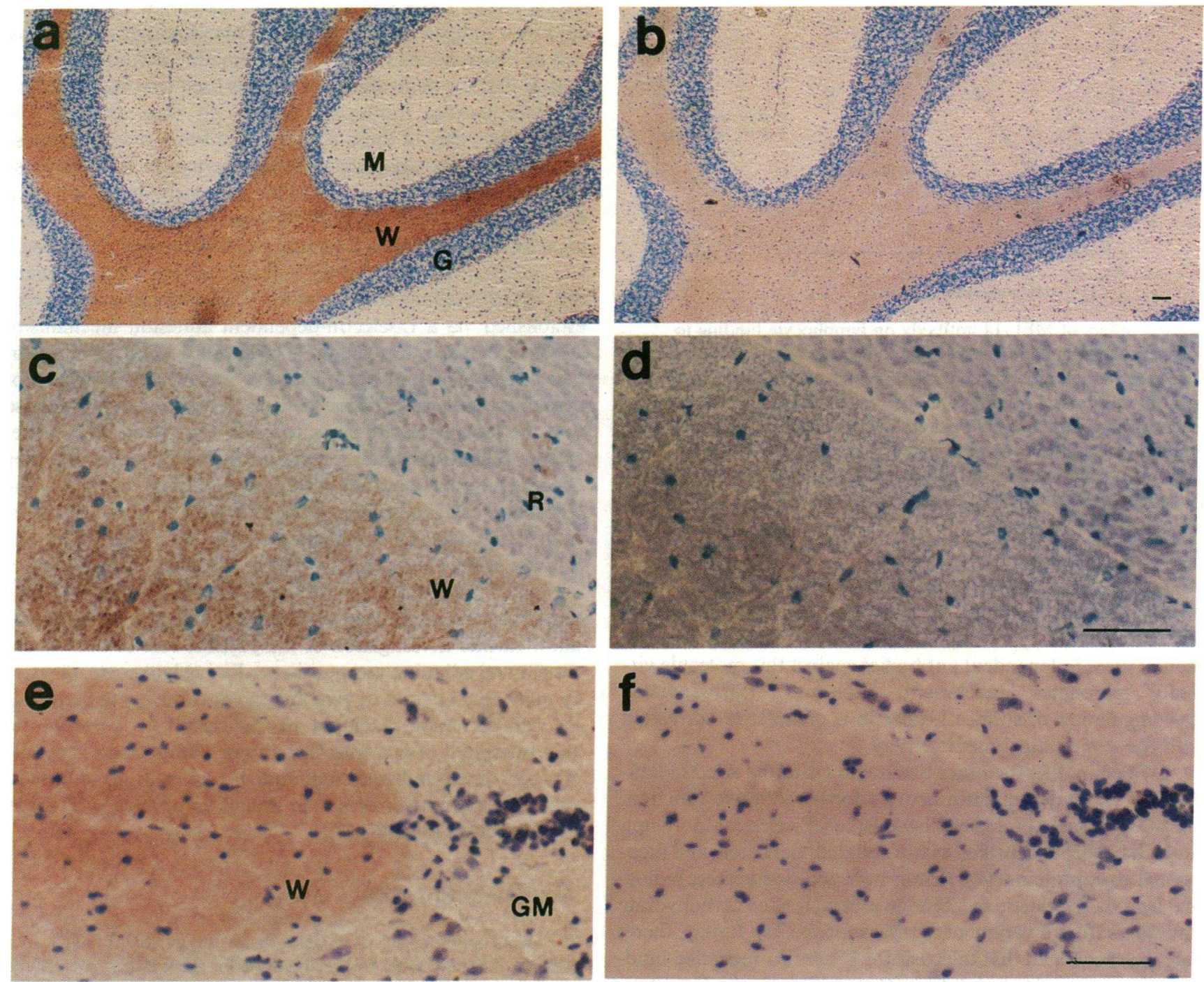

Figure 2. LEC-IgG staining of mouse cerebellum and spinal cord. ( $a$ and $b$ ) Cerebellum; $(c$ to $f)$ spinal cord. ( $a, c$, and $e$ ) No EGTA added; (b, $d$, and $f$ ) with $10 \mathrm{mM}$ EGTA. $W$, white matter, $G$, granular layer, and $M$, molecular layer. In $c$ and $d$, the lower left portion represents an area of white matter of the spinal cord, and the upper right portion represents an adjacent nerve root $(R) . e$ and $f$ show the anterior funiculus (an area consisting of the white matter) and central canal surrounded by grey matter $(G M)$. The reaction product for the HRP immunohistochemistry is brown in these micrographs. Nuclei within the sections stain blue as a result of counterstaining with hematoxylin. Bars, $50 \mu \mathrm{m}$.

effects were observed with TQ1, whether the cerebellar sections were of human or mouse origin. In addition, LAM 1.4 and PolyMEL produced almost complete inhibition of Jurkat cell binding to cerebellar myelin (Table I).

Several integrins, in particular VLA-4 $\left(\alpha_{4} \beta_{1}\right)$, LPAM-1 $\left(\alpha_{4} \beta_{\mathrm{P}}\right)$, and LFA-1 $\left(\alpha_{1} \beta_{2}\right)$, are known to participate in lymphocyte adhesive interactions to a variety of cells including other lymphocytes, endothelial cells, follicular dendritic cells, fibroblasts, and keratinocytes $(16,20,32,33)$. Therefore, to determine whether the observed inhibitory effects were restricted to anti-L-selectin reagents, function-blocking antibodies against $\alpha_{4}, \beta_{1}$, and $\beta_{2}$ were tested for their effects on mouse lymphocyte, human PBL, and human Jurkat cell binding to cerebellar myelin. As shown in Table I, none of these antibodies produced inhibition when tested at saturation.

Further evidence for the involvement of L-selectin in myelin binding came from phorbol ester studies. PMA treatment of human lymphocytes is known to cause a rapid and almost complete shedding of L-selectin from the cell surface, which is presumed to be due to proteolytic cleavage (31). We confirmed this observation for the Jurkat cells by FACS analysis with an anti L-selectin mAb (i.e., TQ1). After down modulation of Lselectin, binding to cerebellar myelin tract and to PN HEV were both drastically reduced (Table II).

\section{Discussion}

The present results indicate a role for L-selectin in the in vitro attachment of lymphocytes to myelinated regions of CNS. Ligand sites for L-selectin are concentrated in white matter regions of CNS, where myelinated axons are abundant. In the case of mouse lymphocytes, the contribution of L-selectin appears to be partial in view of the incomplete inhibition by either a monoclonal or a polyclonal antibody. The finding that mouse lymphocyte binding is greatly reduced by EGTA suggests the possible participation of other calcium-dependent re- 


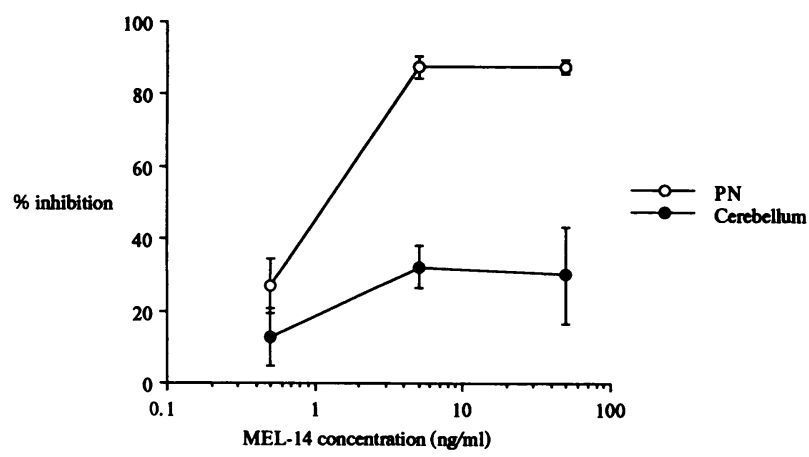

Figure 3. Effect of MEL-14 antibody on lymphocyte binding to mouse cerebellum. Mouse MLN lymphocytes were mixed with FITC-labeled rat lymphocytes (used as an internal control population) for the binding assay. MEL-14 antibody was added to the cells at the indicated concentrations before their incubation with tissue sections. Inhibition of adherence was calculated as the change in the ratio of HEV- or myelin-bound mouse to rat cells. Anti-T200 at $500 \mathrm{ng} / \mathrm{ml}$ did not affect the lymphocyte binding to either PN HEV or cerebellum myelin ( $<5 \%$ change).

ceptors on the same cells or on distinct cell populations. However, in the case of human lymphocytes, L-selectin appears to play a dominant role in attachment to white matter because each of three independent antibodies against this molecule virtually eliminates attachment. Moreover, PMA-induced downregulation of surface L-selectin is completely correlated with the loss of attachment activity.

L-Selectin, like the other two members of the selectin family (34), depends on lectin activity for its adhesive function. HEV-associated, biological ligands for L-selectin in lymph nodes have been identified as two sulfated, sialylated, and fucosylated glycoproteins (12). However, in addition to these biological ligands, L-selectin can bind to several related carbohydrate structures from a variety of natural sources (35). It may, therefore, be speculated that the basis for L-selectin-mediated binding of lymphocytes to white matter of brain is the fortuitous expression of a cross-reactive carbohydrate within the myelinated tracts. Based on the present histochemical studies with LEC-IgG, this putative carbohydrate-based ligand would appear to be present on CNS myelinated tracts but absent or substantially diminished on myelinated peripheral nerves. Whether the putative CNS ligand is an actual constituent of myelin membranes or is expressed on an associated structure remains to be determined by higher resolution morphological mapping.

An interaction between lymphocytes and myelinated tracts, which is reflected in the in vitro assay of the present study, has dubious physiologic significance under normal circumstances, because lymphocytes are largely excluded from the CNS parenchyma (36). However, in demyelinating diseases of the CNS, such as experimental allergic encephalomyelitis (EAE) in animals and MS in humans, lymphocytes and macrophages traffic in large numbers to the CNS and are found in close association with lesions $(37,38)$. The etiology of EAE clearly involves class II restricted, $\mathrm{CD}^{+} \mathrm{T}$ cells that are specific for defined regions of myelin basic protein (36). However, the neuroantigen-specific $T$ cells appear to represent a very small minority of the lymphocytes that invade the brain $(39,40)$. Moreover, the neuroantigen-specific lymphocytes are predominantly restricted to perivascular localizations, whereas the infil- trating lymphocytes contiguous with the actual lesions are of unknown antigen specificity (39). These findings in EAE, as well as observations in other demyelinating diseases (41-43), suggest that the demyelination process itself may involve lymphocytes lacking immune reactivity to neuroantigens, although the entry of these cells into the brain may be orchestrated by neuroantigen-specific lymphocytes $(39,43)$. The present demonstration that L-selectin can mediate lymphocyte attachment to myelinated tracts suggests a potential mechanism for the targeting of lymphocytes (irrespective of their antigen specificity) as well as other leukocytes possessing L-selectin $(44,45)$ to myelinated axons of the CNS. Once proximity were established via a L-selectin-dependent adhesion mechanism, selective damage to myelinated cells could result from a process of cell-mediated cytotoxicity or from the local release of cytokines, proteases, or free radicals. These models presuppose that the leukocytes are activated as cytotoxic or cytokine-secreting cells before their association with myelin or that they become fully activated as a consequence of the association. The restriction of ligand sites to CNS as opposed to the PNS white matter may offer an explanation of why many demyelinating diseases selectively affect the CNS. The availability of a wide variety of reagents (e.g., antibodies, carbohydrates, LEC-IgG) that block the interaction of L-selectin with its ligands should allow further investigation of the possible role of this widelydistributed adhesion receptor in mediating leukocyte adhesion to myelinated nerves in vivo and in contributing to pathological demyelination reactions. In this regard, it is noteworthy that treatment of rats with fucoidin or mannose-6-phosphate, two carbohydrate-based inhibitors of L-selectin, have been reported to prevent or delay the induction of adoptively transferred EAE in rats $(46,47)$.

\section{Acknowledgments}

We thank Larry Lasky of Genentech for the gift of LEC-IgG, Tom Tedder of Dana Farber Cancer Institute for the gift of LAM 1.4 antibody, and Caroline Damsky of University of California, San Francisco for the gift of AIIB2 antibody. Lloyd Stoolman kindly provided the Jurkat cell line used in this study. We thank Ted Yednock of Athena Neurosciences for many helpful discussions.

The research was supported by grants from the National Institutes of Health (NIH) (GM23547 and Multipurpose Arthritis Center Grant P60 AR20684) and Genentech, Inc., to S. D. Rosen and by an NIH Postdoctoral Fellowship (F32 AR08019) to J. S. Geoffroy.

\section{References}

1. Yednock, T. A., and S. D. Rosen. 1989. Lymphocyte homing. Adv. Immunol. 44:313-378.

2. Berg, E. L., L. A. Goldstein, M. A. Jutila, M. Nakache, L. J. Picker, P. R. Streeter, N. W. Wu, D. Zhou, and E. C. Butcher. 1989. Homing receptors and vascular addressins: cell adhesion molecules that direct lymphocyte traffic. Immunol. Rev. 108:5-18.

3. Woodruff, J. J., L. M. Clarke, and Y. H. Chin. 1987. Specific cell-adhesion mechanisms determining migration pathways of recirculating lymphocytes. Annu. Rev. Immunol. 5:201-222.

4. Gallatin, W. M., I. L. Weissman, and E. C. Butcher. 1983. A cell surface molecule involved in organ-specific homing of lymphocytes. Nature (Lond.). 303:30-34.

5. Lasky, L. A., M. S. Singer, T. A. Yednock, D. Dowbenko, C. Fennie, H. Rodriguez, T. Nguyen, S. Stachel, and S. D. Rosen. 1989. Cloning of a lymphocyte homing receptor reveals a lectin domain. Cell. 56:1045-1055.

6. Siegelman, M. H., M. Van De Rijn, and I. L. Weissman. 1989. Mouse lymph node homing receptor cDNA clone encodes a glycoprotein revealing tandem interaction domains. Science (Wash. DC). 243:1165-1172. 
7. Bowen, B. R., T. Nguyen, and L. A. Lasky. 1989. Characterization of a human homologue of the murine peripheral lymph node homing receptor. J. Cell Biol. 109:421-427.

8. Siegelman, M. H., I. C. Cheng, I. L. Weissman, and E. K. Wakeland. 1990 The mouse lymph node homing receptor is identical with the lymphocyte cell surface marker Ly-22: role of the EGF domain in endothelial binding. Cell. 61:611-622.

9. Tedder, T. F., C. M. Isaacs, T. J. Ernst, G. D. Demetri, D. A. Adler, and C. M. Disteche. 1989. Isolation and chromosomal localization of cDNAs encoding a novel human lymphocyte cell surface molecule, LAM-1. Homology with the mouse lymphocyte homing receptor and other human adhesion proteins. $J$. Exp. Med. 170:123-133.

10. Camerini, D., S. P. James, I. Stamenkovic, and B. Seed. 1989. Leu-8/TQ is the human equivalent of the Mel-14 lymph node homing receptor. Nature (Lond.). 342:78-82.

11. Kishimoto, T. K., M. A. Jutila, and E. C. Butcher. 1990. Identification of a human peripheral lymph node homing receptor: a rapidly down-regulated adhesion molecule. Proc. Natl. Acad. Sci. USA. 87:2244-2248.

2. Imai, Y., M. S. Singer, C. Fennie, L. A. Lasky, and S. D. Rosen. 1991. Identification of a carbohydrate-based endothelial ligand for a lymphocyte homing receptor. J. Cell Biol. 113:1213-1221.

2a. Berg, E. L., M. K. Robinson, R. A. Warnock, and E. C. Butcher. 1991. The human peripheral lymph node vascular addressin is a ligand for LECAM-1, the peripheral lymph node homing receptor. J. Cell Biol. 114:343-349.

13. Stoolman, L. M. 1989. Adhesion molecules controlling lymphocyte migration. Cell. 56:907-910.

14. Chin, Y. H., R. Rasmussen, J. J. Woodruff, and T. G. Easton. 1986. A monoclonal anti-HEBFpp with specificity for lymphocyte surface molecules mediating adhesion to Peyer's patch high endothelium of the rat. J. Immunol. 136:2556-2561.

15. Jalkanen, S., R. F. Bargatze, J. de los Toyos, and E. C. Butcher. 1987. Lymphocyte recognition of high endothelium: antibodies to distinct epitopes of an 85-95-kD glycoprotein antigen differentially inhibit lymphocyte binding to lymph node, mucosal, or synovial endothelial cells. J. Cell Biol. 105:983-990.

16. Holzmann, B., B. W. McIntyre, and I. L. Weissman. 1989. Identification of a murine Peyer's patch-specific lymphocyte homing receptor as an integrin molecule with an alpha chain homologous to human VLA-4. Cell. 56:37-46.

17. Jalkanen, S., A. C. Steere, R. I. Fox, and E. C. Butcher. 1986. A distinct endothelial cell recognition system that controls lymphocyte traffic into inflamed synovium. Science (Wash. DC). 233:556-558.

18. Stamper, H. B., Jr., and J. J. Woodruff. 1976. Lymphocyte homing into lymph nodes: in vitro demonstration of the selective affinity of recirculating lymphocytes for high-endothelial venules. J. Exp. Med. 144:828-833.

19. Butcher, E. 1986. The regulation of lymphocyte traffic. Curr. Top. Microbiol. Immunol. 128:85-122.

20. Freedman, A. S., J. M. Munro, G. E. Rice, M. P. Bevilacqua, C. Morimoto, B. W. McIntyre, K. Rhynhart, J. S. Pober, and L. M. Nadler. 1990. Adhesion of human B cells to germinal centers in vitro involves VLA-4 and INCAM110. Science (Wash. DC). 249:1030-1033.

21. Kuttner, B. J., and J. J. Woodruff. 1979. Selective adherence of lymphocytes to myelinated areas of rat brain. J. Immunol. 122:1666-1671.

22. Dore-Duffy, P., V. Goertz, and B. L. Rothman. 1980. Lymphocyte adherence to myelinated tissue in multiple sclerosis. J. Clin. Invest. 66:843-846.

23. Geoffroy, J. S., and S. D. Rosen. 1989. Demonstration that a lectin-like receptor ( $\mathrm{gp} 90^{\mathrm{MEL}}$ ) directly mediates adhesion of lymphocytes to high endothelial venules of lymph nodes. J. Cell Biol. 109:2463-2469.

24. Watson, S. R., Y. Imai, C. Fennie, J. S. Geoffroy, S. D. Rosen, and L. A. Lasky. 1990. A homing receptor-IgG chimera as a probe for adhesive ligands of lymph node high endothelial venules. J. Cell Biol. 110:2221-2229.

25. Ley, K., P. Gaehtgens, C. Fennie, M. S. Singer, L. A. Lasky, and S. D. Rosen. 1991. LEC-CAM1 mediates leukocyte rolling in mesenteric venules in vivo. Blood. 77:2553-2555.

26. Hall, D. E., L. F. Reichardt, E. Crowley, B. Holley, H. Moezzi, A. Sonnen- berg, and C. H. Damsky. 1990. The $\alpha_{1} / \beta_{1}$ and $\alpha_{6} / \beta_{1}$ integrin heterodimers mediate cell attachment to distinct sites on laminin. J. Cell Biol. 110:2175-2184.

27. Stoolman, L. M., T. S. Tenforde, and S. D. Rosen. 1984. Phosphomannosyl receptors may participate in the adhesive interactions between lymphocytes and high endothelial venules. J. Cell Biol. 99:1535-1540.

28. Butcher, E., R. Scollay, and I. Weissman. 1979. Lymphocyte adherence to high endothelial venules: characterization of a modified in vitro assay, and examination of the binding of syngeneic and allogeneic lymphocyte populations. $J$. Immunol. 123:1996-2003.

29. Woodruff, J., H. Katz, L. Lucas, and H. Stamper. 1977. An in vitro model of lymphocyte homing. J. Immunol. 119:1603-1664.

30. Yednock, T. A., L. M. Stoolman, and S. D. Rosen. 1987. Phosphomannosyl-derivatized beads detect a receptor involved in lymphocyte homing. $J$. Cell Biol. 104:713-724.

31. Tedder, T. F., A. C. Penta, H. B. Levine, and A. S. Freedman. 1990 Expression of the human leukocyte adhesion molecule, LAM1. Identity with the TQ1 and Leu-8 differentiation antigens. J. Immunol. 144:532-540.

32. Hemler, M. E. 1990 . VLA proteins in the integrin family: structures, functions, and their role on leukocytes. Annu. Rev. Immunol. 8:365-400.

33. Springer, T. A. 1990 . Adhesion receptors of the immune system. Nature (Lond.). 346:425-434.

34. Springer, T. A., and L. A. Lasky. 1991. Cell adhesion: sticky sugars for selectins. Nature (Lond.). 349:196-197.

35. Imai, Y., D. D. True, M. S. Singer, and S. D. Rosen. 1990. Direct demonstration of the lectin activity of $\mathrm{gp} 90^{\mathrm{MEL}}$, a lymphocyte homing receptor. J. Cell Biol. 111:1225-1232.

36. Zamvil, S. S., and L. Steinman. 1990. The T lymphocyte in experimental allergic encephalomyelitis. Annu. Rev. Immunol. 8:579-621.

37. Traugott, U., E. Reinherz, and C. S. Raine. 1983. Multiple sclerosis: distribution of $\mathrm{T}$ cell subsets within active chronic lesions. Science (Wash. DC). 219:308-310.

38. Traugott, U., D. E. McFarlin, and C. S. Raine. 1986. Immunopathology of the lesion in chronic relapsing experimental autoimmune encephaliomyelitis in the mouse. Cell. Immunol. 99:395-410.

39. Cross, A. H., B. Cannella, C. F. Brosnan, and C. S. Raine. 1990. Homing to central nervous system vasculature by antigen-specific lymphocytes. I. Localization of ${ }^{14} \mathrm{C}$-labeled cells during acute, chronic, and relapsing experimental allergic encephalomyelitis. Lab. Invest. 63:162-170.

40. Werdelin, $O$, and R. T. McCluskey 1971. The nature and the specificity of mononuclear cells in experimental autoimmune inflammations and the mechanisms leading to their accumulation. J. Exp. Med. 133:1242-1263.

41. Wisniewski, H. M., and B. R. Bloom. 1975. Primary demyelination as a nonspecific consequence of cell-mediated immune reaction. J. Exp. Med. 141:346-359.

42. Miller, S. D., R. J. Clatch, D. C. Pevear, J. L. Trotter, and H. L. Lipton. 1987. Class II-restricted T cell responses in Theiler's murine encephalomyelitis virus (TMEV)-induced demyelinating disease. I. Cross-specificity among TMEV substrains and related picornaviruses, but not myelin proteins. J. Immunol. 138:3776-3784

43. Swanborg, R. H. 1990. Horror autotoxicus and homing: implications for autoimmunity. Lab. Invest. 63:141-143.

44. Lewinsohn, D. M., R. F. Bargatze, and E. C. Butcher. 1987. Leukocyte-endothelial cell recognition: evidence of a common molecular mechanism shared by neutrophils, lymphocytes, and other leukocytes. J. Immunol. 138:4313-4321.

45. Ord, D. C., T. J. Ernst, L. J. Zhou, A. Rambaldi, O. Spertini, J. Griffin, and T. F. Tedder. 1990. Structure of the gene encoding the human leukocyte adhesion molecule-1 (TQ1, Leu-8) of lymphocytes and neutrophils. J. Biol. Chem. 265:7760-7767.

46. Willenborg, D. O., and C. R. Parish. 1988. Inhibition of allergic encephalomyelitis in rats by treatment with sulfated polysaccharides. J. Immunol. 140:3401-3405.

47. Willenborg, D. O., C. R. Parish, and W. B. Cowden. 1989. Phosphosugars are potent inhibitors of central nervous system inflammation. FASEB (Fed. Am. Soc. Exp. Biol.) J. 3:1968-1971. 